Article

\title{
An Innovative Bioceramic Bone Graft Substitute for Bone Defect Treatment: In Vivo Evaluation of Bone Healing
}

\author{
Syamsiah Syam 1,2®, Yung-Chieh Cho ${ }^{2,3}$, Chung-Ming Liu ${ }^{1,2}$, Mao-Suan Huang ${ }^{4,5}$, \\ Wen-Chien Lan ${ }^{6}$, Bai-Hung Huang ${ }^{2,7,8}$, Takaaki Ueno ${ }^{9}$, Chi-Hsun Tsai ${ }^{10}$, Takashi Saito 10 (D), \\ May-Show Chen ${ }^{3,11, *}$ and Keng-Liang $\mathrm{Ou}^{2,4,6,9,12, * \text { (D) }}$ \\ 1 Graduate Institute of Dental Science, College of Dentistry, China Medical University, Taichung 404, Taiwan; \\ u108312101@cmu.edu.tw (S.S.); liuc@mail.cmu.edu.tw (C.-M.L.) \\ 2 Biomedical Technology R \& D Center, China Medical University Hospital, Taichung 404, Taiwan; \\ D204106003@tmu.edu.tw (Y.-C.C.); T33782@mail.cmuh.org.tw (B.-H.H.) \\ 3 School of Dentistry, College of Oral Medicine, Taipei Medical University, Taipei 110, Taiwan \\ 4 Department of Dentistry, Taipei Medical University-Shuang Ho Hospital, New Taipei City 235, Taiwan; \\ hms4837@tmu.edu.tw \\ 5 School of Oral Hygiene, College of Oral Medicine, Taipei Medical University, Taipei 110, Taiwan \\ 6 Department of Oral Hygiene Care, Ching Kuo Institute of Management and Health, Keelung 203, Taiwan; \\ jameslan@ems.cku.edu.tw \\ 7 Asia Pacific Laser Institute, New Taipei City 220, Taiwan \\ 8 Implant Academy of Minimally Invasive Dentistry, Taipei 106, Taiwan \\ 9 Department of Dentistry and Oral Surgery, Osaka Medical College, Osaka 569-8686, Japan; \\ ueno@osaka-med.ac.jp \\ 10 Division of Clinical Cariology and Endodontology, Department of Oral Rehabilitation, School of Dentistry, \\ Health Sciences University of Hokkaido, Hokkaido 061-0293, Japan; e526095019@tmu.edu.tw (C.-H.T.); \\ t-saito@hoku-iryo-u.ac.jp (T.S.) \\ 11 Division of Prosthodontics, Department of Dentistry, Taipei Medical University Hospital, Taipei 110, Taiwan \\ 12 3D Global Biotech Inc. (Spin-off Company from Taipei Medical University), New Taipei City 221, Taiwan \\ * Correspondence: maychen@tmu.edu.tw (M.-S.C.); klou@tmu.edu.tw (K.-L.O.)
}

Received: 21 October 2020; Accepted: 20 November 2020; Published: 23 November 2020

\begin{abstract}
This study aimed to analyze characteristics of an innovative $\alpha$-calcium sulfate hemihydrate $(\alpha-\mathrm{CSH})$ bioceramic and bone healing and regeneration characteristics following its implantation on artificially created defects of rat models and human jaw defects. The $\alpha$-CSH bioceramic was characterized using field emission scanning electron microscope (FE-SEM), energy-dispersive spectroscopy (EDS), and thermal-imaging instruments. The material was implanted on artificially created defects in a rat's right hind leg bone and observed histologically after three days and seven weeks. The material was also implanted in patients with bone defects in the posterior maxillary, then observed immediately and six months post-treatment by panoramic and computed tomography image. The FE-SEM confirm this material is a uniform-shaped short column crystal, while the EDS measurement reveals calcium as the most component in this material. Thermal observation shows temperature change during the setting time is less than $2{ }^{\circ} \mathrm{C}$, and the maximum temperature reached is $31^{\circ} \mathrm{C}$. In the histological analysis, $\alpha$-CSH bioceramic shows new trabecular bone formation and absorbed material at seven weeks post-treatment. Moreover, panoramic and computed tomography image shows intact bone six months post-treatment. Therefore, this study suggests that the innovative $\alpha$-CSH bioceramic can be useful in bone defect treatment.
\end{abstract}

Keywords: $\alpha$-calcium sulfate hemihydrate; bioceramic; bone graft; bone defect treatment; bone healing; bone regeneration 


\section{Introduction}

Bone defects are often associated with inadequate or absence of bone tissue in a body area where the area should be normal bone $[1,2]$. Bone defects can occur due to various causes, such as traumatic injury, a congenital defect, or surgical intervention of infection or tumor resection [3-10]. Moreover, bone defects also often occur in the jaw after tooth extraction, especially in the posterior maxillary region, because the bone in this region is bordered by the floor of the sinus and crest of the alveolar bone that causes height bone loss after tooth extraction [3,5-7,11-17]. A lack of bone volume in the jaw makes dental implant placement impossible [7,11,12,16-21]. Currently, bone defects are still a difficult problem and become a concern for both orthopedics and oral surgeons because of the potential risk of complications $[1,2,6,10,13,15,17,22-25]$. One of the bone defect treatments is bone reconstruction with a bone graft that can regenerate bone and restore the function of the area affected by the defect $[3,4,15,19,20,26]$.

A bone graft is an implanted material that not only serves to promote bone healing but, also, to contour augmentation $[13,16]$. Thus, this material should have osteoconduction, osteoinduction, osteogenic, and osseointegration properties $[1,3,4,8,13,16]$. Furthermore, bone graft material should be easy and safe to use $[1,3,4]$. Although autologous bone graft is still the gold standard for bone reconstruction, however, some disadvantages have been reported to cause discomfort to the patient, and it will increase the treatment costs $[1,3,7-9,14,16,20,24,27]$. Xenograft bone blocks have been reported to be good alternatives to autologous bone grafts that can increase the bone volume both horizontally and vertically via an on-lay or inlay grafting procedure [28-31]. One study showed that a xenograft bone block increased the vertical bone volume in the inlay graft technique without the use of a fixation devices, which could lead to the risk of fracture in the bone segment [31]. However, the use of bone block xenografts potentially causes disease transmission or allergic reactions in the patient, requiring shape adjustment; the recipient area requires additional contouring, and the remaining space needs to be filled with bone particles [28-31]. Another alternative to bone reconstruction that has been widely suggested is the use of synthetic bone substitutes $[1,4,9,15,19,22]$.

The use of calcium sulfate hemihydrate bioceramic has been widely used in medical applications such as bone grafts, repairing root perforations, root-end filling materials, drug carriers, and also, potential as three-dimensional printing materials for scaffold manufacture in bone tissue engineering due to its excellent properties, especially in osteoinduction [32-35]. Other advantages of using calcium sulfate clinically include the usefulness for local hemostasis after dental extraction even in patients on anticoagulant therapy without stopping the therapy before surgery and, also, for local hemostasis in endodontic microsurgery [36-39]. In previous studies, we used an innovative $\alpha$-calcium sulfate hemihydrate $(\alpha-\mathrm{CSH})$ bioceramic as a bone graft substitute that is similar in nature to autologous bone grafts, and these studies also indicated that $\alpha$-CSH bioceramic is safe to use in clinical applications, since this material is a nonirritant and has no risk of immunological rejection [40]. Our other previous study showed the potential safety of using $\alpha$-CSH bioceramic, since this material is microwave-synthesized high-purity $\alpha$-CSH without using any chemical reagents, and the cytotoxicity assay results demonstrated that this material does not affect the proliferation of L929 cells [41]. Moreover, that study clearly showed the formation of angiogenesis, which is important for osseointegration and the healing process [41]. Therefore, the present study aimed to further investigate the thermal behavior, bone healing, and regeneration characteristics (rat model and clinical application) of the innovative $\alpha$-CSH bioceramic for bone defect treatments.

\section{Materials and Methods}

\subsection{Materials}

The analyzed material in this study used a high-purity $\alpha$-CSH bioceramic that was synthesized from calcium sulfate dihydrate (CSD) by a microwave-irradiation approach without using any chemical reagents, as reported in our previous study $[40,41]$. To synthesize $\alpha$-CSH, CSD powder (2 g) was mixed 
with deionized water $(10 \mathrm{~mL})$. The mixture and the magnetic stirring bar were put in a Teflon pressure tube ( $55 \mathrm{~mL}, \sim 350 \mathrm{psi})$, then microwaved $\left(800 \mathrm{~W}\right.$ ) at $160^{\circ} \mathrm{C}$ for $10 \mathrm{~min}$. The synthesized sample was filtered, cleaned with ethanol, dried in an oven at $60^{\circ} \mathrm{C}$ for $8 \mathrm{~h}$, and grounded as powder [41].

\subsection{Material Characterizations}

Sample for morphology observation and composition analysis was placed on the copper grid sample holder. Before being loaded into the sample chamber, a platinum thin film with a thickness of $30 \mathrm{~nm}$ was sputter-coated on the sample surface to enhance electrical conductivity. Afterward, the sample was observed by field emission scanning electron microscope (FE-SEM; JEOL, JSM-6500F, Tokyo, Japan) at an accelerating voltage of $20 \mathrm{kV}$, while the chemical composition was analyzed by INCA energy-dispersive spectroscopy (EDS, Oxford instruments, Abingdon, UK). Moreover, temperature variation during the setting time of the sample was measured by thermal imaging infrared camera (Advanced Thermo TVS-500EX, Nippon Avionics Co., Ltd., Yokohama, Japan). Sample with a weight of $0.3 \mathrm{~g}$ was mixed with 5-mL normal saline (Sigma-Aldrich, Taipei, Taiwan), and then shaped into a spherical pellet. Subsequently, the temperature of the spherical pellet was recorded at room temperature of $25^{\circ} \mathrm{C}$ using the TVS-500EX infrared camera fifteen centimeters from the pellet.

\subsection{Animal Study}

The protocols for animal experiments were reviewed and approved by the Institutional Animal Care and Use Committee for Taipei Medical University under a project identification code of LAC-2015-0073. Twenty-four Sparague-Dawley rats weighing 200-300 g obtained from BioLASCO Co., Ltd. (Taipei, Taiwan) were used in this study. The Sparague-Dawley rats were divided into three groups according to the type of implantation materials, consisting of the testing article (TA; the innovate $\alpha$-CSH bioceramic) group, commercial product (CP; Merries Uni-Osteo, J.O. Corporation, New Taipei City, Taiwan) group [40], and blank group. The implantation procedure was conducted under general anesthesia using isoflurane inhalation. The implantation of approximately 0.1-g powder of $\alpha$-CSH bioceramic bone graft substitute testing article $(n=4)$ and commercial predicate material $(n=4)$ were randomly implanted in the rat's right hind leg bones after created artificial defects by drilling (diameter: $2 \mathrm{~mm}$ and depth: $2 \mathrm{~mm}$ ), while in the blank group $(n=4)$, artificially created defects were left without any implanted materials, and radiography was taken immediately after implantation (Figure 1). The animal was sacrificed according to the observational period (3 days and 7 weeks after treatment). A short-term healing observation was used to investigate its early-stage bone healing and inflammatory response.

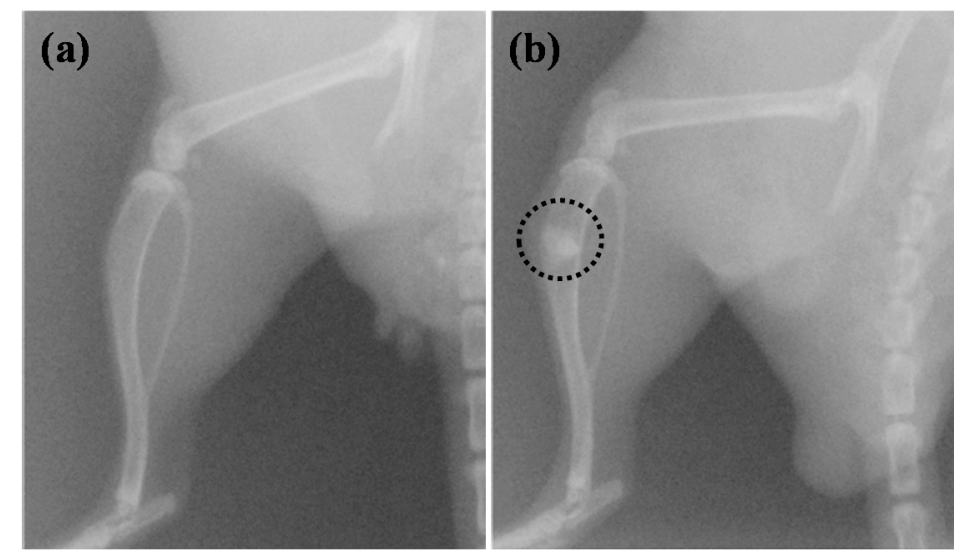

Figure 1. The position of the implanted material in the rat's right hind leg bones: (a) before implantation and (b) after implantation (as indicated by the black dash line). 


\subsection{Histological Analysis}

Following sacrificing, artificially created defects in the rat's right hind leg bones and their implants were subjected to histological analysis. The samples were fixed in $10 \%$ neutral-buffered formalin, dehydrated in ethanol, embedded in paraffin wax, trimmed, and stained with hematoxylin and eosin (H\&E). Then, the stained slides were evaluated by optical microscopy (Olympus BX51, Tokyo, Japan) under different magnifications.

\subsection{Bone Defect Treatment Analysis in Patient with Height Bone Loss in the Posterior Maxillary}

The protocols for clinical investigations were reviewed and approved by the Taipei Medical University-Joint Institutional Review Board under a project identification code of TMU-JIRB 201301009. The GCP has been followed together with ISO 14155 prescriptions during clinical study. Patients $(n=10)$ with height bone loss in the posterior maxillary were recruited for investigation in this study. Bone defect in the left posterior maxillary exposed under local anesthesia to perform sinus lifting with the Luc-Caldwell procedure. The lateral window was performed on the lateral wall of the maxillary sinus, lateral wall of the sinus in-fractured, membrane lifted from the sinus floor, and implant placed simultaneously. The $\alpha$-CSH bone graft substitute was filled in the defect area to cover the lateral window (Figure 2a) and, subsequently, put the concentrated growth factor (CGF) membrane on the filled $\alpha$-CSH bone graft substitute (Figure $2 b$ ), then sutured. The bone regeneration was observed at immediately and 6 months post-treatment by panoramic and computed tomography (CT) image.
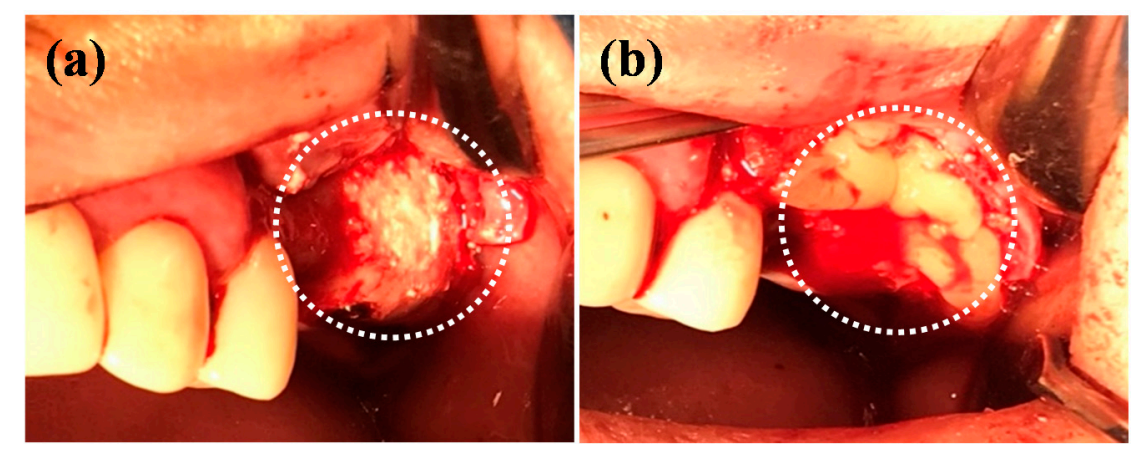

Figure 2. (a) Application of $\alpha$-calcium sulfate hemihydrate ( $\alpha$-CSH) bioceramic bone graft substitute in a lateral window and (b) covered by a concentrated growth factor (CGF) membrane.

\section{Results and Discussion}

\subsection{Morphology of the Innovate $\alpha$-CSH Bioceramic}

Figure 3 illustrates the morphology and chemical compositions of the $\alpha$-CSH bioceramic bone graft substitute material that was used in the present study. The FE-SEM image of $\alpha$-CSH bioceramic revealed a uniform-shaped short column crystal around $10 \mu \mathrm{m}$ in length (Figure 3a). The morphology of $\alpha$-CSH bioceramic was organized by a microwave irradiation treatment on CSD at $160^{\circ} \mathrm{C}$ for $10 \mathrm{~min}$, which resulted in changes in the morphology of CSD crystals from tablet-like to a uniform short column and, also, changes in the crystal structure from monoclinic to hexagonal [41]. The EDS measurements (Figure $3 b$ ) recognizing calcium as the most component in this material, with an average content value of $37.51 \mathrm{wt} . \%$, which is very important in bone formation [25,40,41]. In addition to the calcium element, the main composition of sulfate $(27.52 \mathrm{wt} . \%)$ can also be detected. No other impurity substances were detected in the $\alpha$-CSH bioceramic. It is noticed that the copper element was generated from the copper grid, which was used as a sample holder for the FE-SEM analysis. 


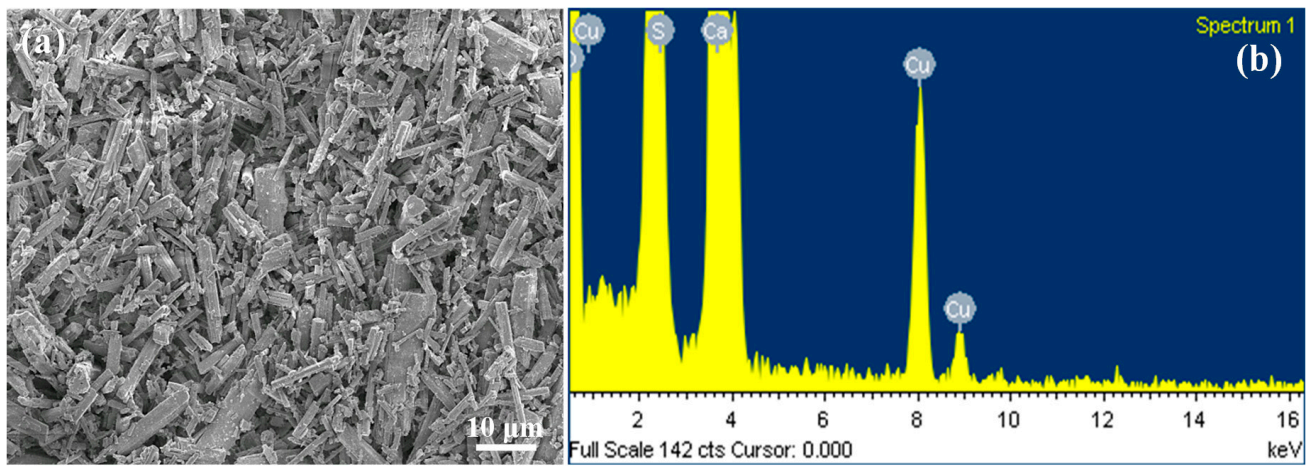

Figure 3. Characteristics of the $\alpha-\mathrm{CSH}$ bioceramic bone graft substitute material: (a) field emission scanning electron microscope (FE-SEM) micrograph and (b) energy-dispersive spectroscopy (EDS) spectrum.

\subsection{Thermal Observation in the Setting Process}

Figure 4 displays the thermal behavior of $\alpha$-CSH bioceramic during the setting time. Clearly, during 5, 10, 15, 20, and 25-min setting time, the $\alpha$-CSH bioceramic experienced a temperature change only less than $2{ }^{\circ} \mathrm{C}$ (Figure 4a); the material began to set at $5 \mathrm{~min}$, and the maximum temperature at 18 min during the setting time was about $31^{\circ} \mathrm{C}$ (Figure $4 \mathrm{~b}$ ). The thermal behavior demonstrated by the $\alpha$-CSH bioceramic included a quick setting and lower temperature variations during the setting time, which are beneficial properties as a bone graft material. Due to the low temperature, this material is safe to use as a bone graft, because it does not cause protein denaturation that will lead to bone damage $[22,35,42,43]$. A quick setting also can speed up the healing process as various proteins and growth factors are absorbed in the blood to the affected area $[40,44]$.
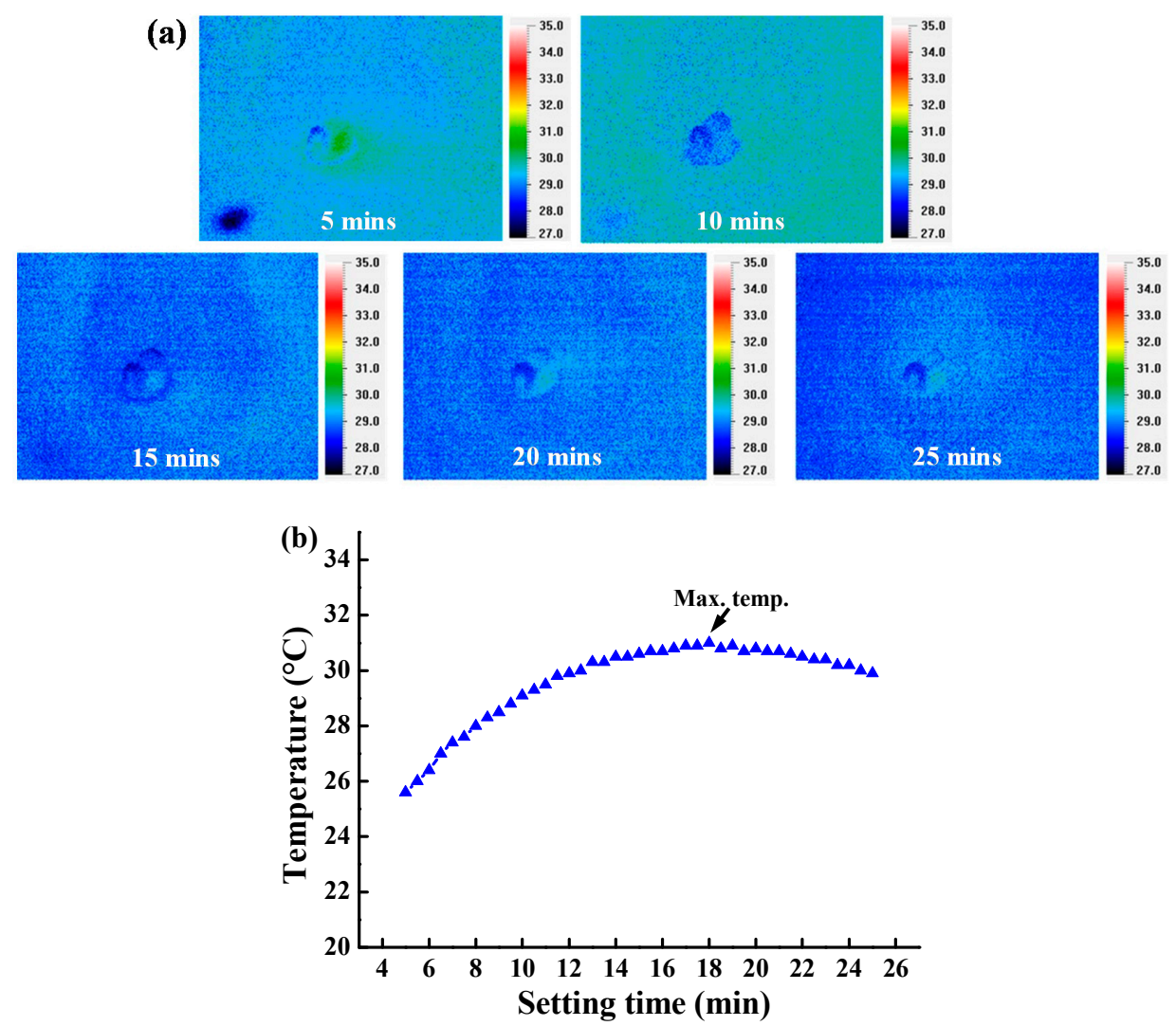

Figure 4. (a) Thermal images of the $\alpha-\mathrm{CSH}$ bioceramic during the setting time and (b) the relationship between the maximum temperature and setting time. 


\subsection{Bone Healing and Regeneration Characteristic of the Materials in the Animal Study}

The histologic finding of $\alpha$-CSH bioceramic under H\&E staining is exhibited in Figure 5. On the third day post-treatment, there was no visible inflammatory process in each study group, while the remaining implanted material was observed in both the TA and CP groups. The presence of inflammatory cells, new trabecular bone formation, and the evidence of absorbed implanted materials in both the TA and CP groups were observed at the seventh week post-treatment. However, the number of inflammatory cells that migrated to the defect area was greater in the TA group. These conditions will promote the inflammatory phase leading to the healing process $[45,46]$. The absorption of $\alpha-\mathrm{CSH}$ bioceramic is related to the formation of new bone, because the defect can absorb calcium from this material, which plays an important role in the demineralization process [40,41]. In our previous study, we confirmed that bioceramic $\alpha-\mathrm{CSH}$ absorption occurred at the fourth week post-treatment [40]. However, the current study showed that all implanted materials absorbed at the seventh week post-treatment.

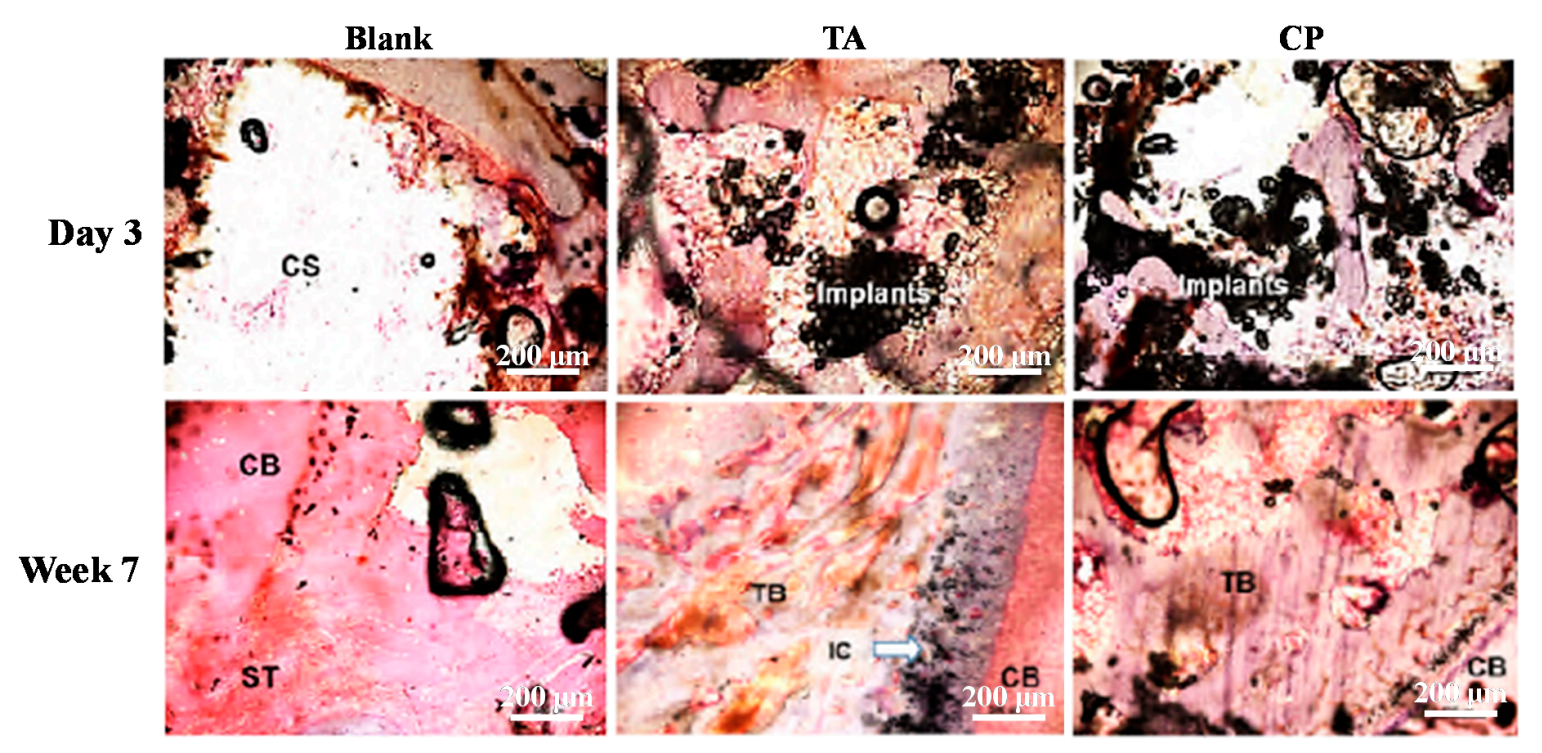

Figure 5. Histological images of $\alpha$-CSH bioceramic at day 3 and week 7 after implantation. (Critical size defect: CS, cortical bone: $\mathrm{CB}$, trabecula bone: TB, immune cell: IC, testing article: TA, commercial product: $\mathrm{CP}$, and soft tissue: $\mathrm{ST})$.

\subsection{Bone Healing and Regeneration Characteristisc of the Materials in the Clinical Application}

Figure 6 shows a panoramic image of the patient before and after obtaining a bone graft. A vertical bone loss in the posterior maxillary region (Figure 6a) caused the sinus lifting, and an additional bone graft was required to obtain adequate bone volume before implant placement $[12,15,20]$. The panoramic image immediately after sinus lifting and the implant of a bone graft material (Figure 6b) indicate that the bone graft material fills the space after sinus lifting. At the six months of follow-up after treatment, the bones in the implanted area were more radiopaque, and all of the bone graft material was absorbed. 

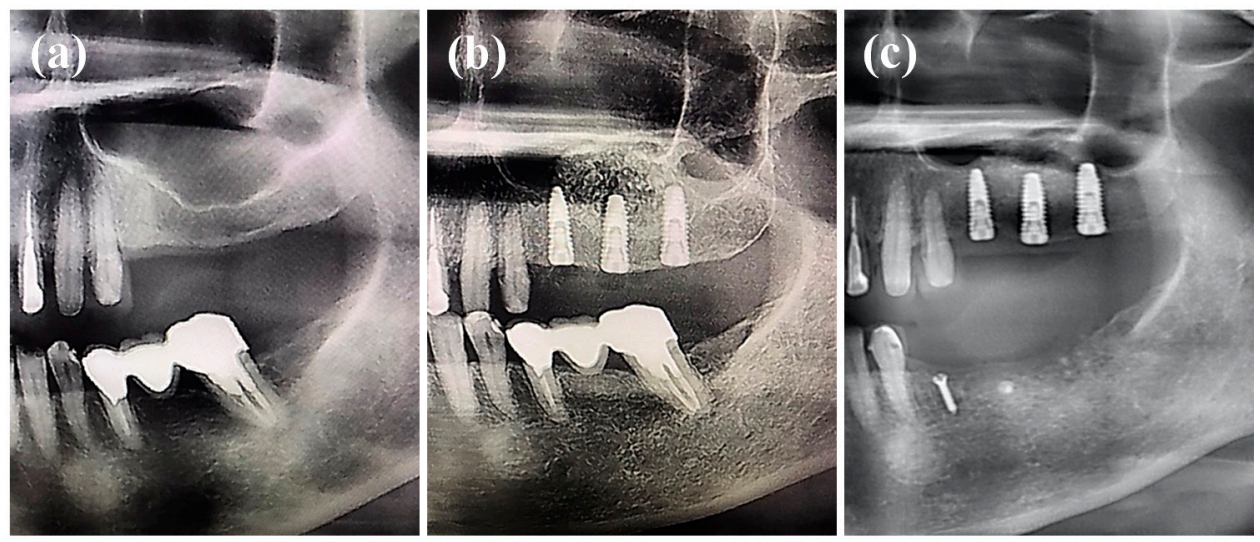

Figure 6. Panoramic images: (a) before treatment, (b) immediately after treatment, and (c) six months after treatment.

The cone-beam CT images before treatment also showed a vertical bone loss in the posterior maxillary region (Figure 7). In the jaw, the maxilla region is the most frequently experiencing vertical bone loss and the most difficult to treat [11,12]. Therefore, both moderate and severe bone loss in this region require a bone graft to treat it [47].

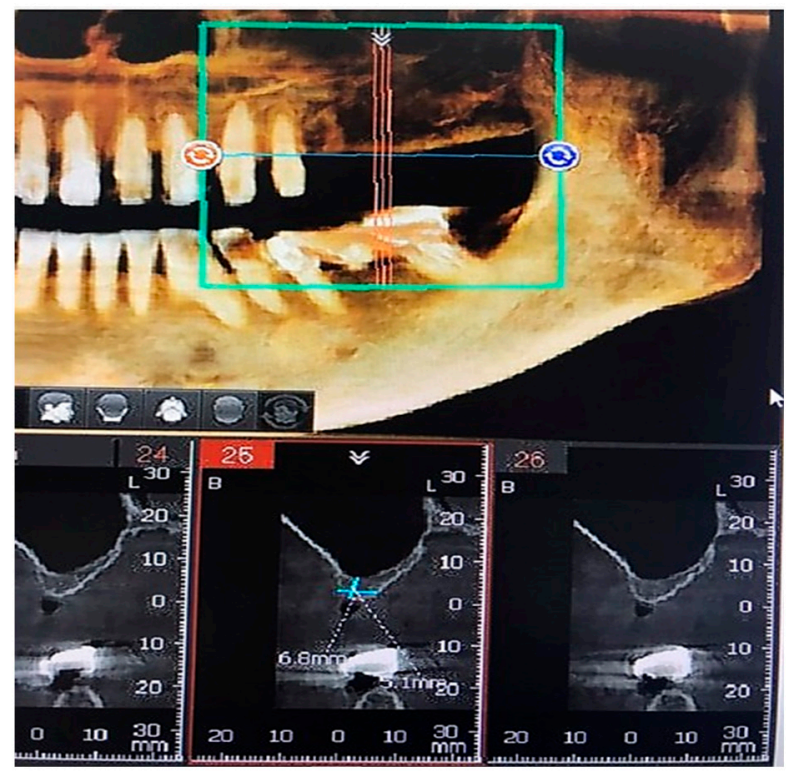

Figure 7. Cone-beam computed tomography (CT) images before treatment.

The cone-beam CT images six months follow-up after treatment are presented in Figure 8, which exhibits the presence of ossification in the defect area. Figure 8a shows a cone-beam CT image representing a clinical case six months after bone graft placement in the left maxillary region, while Figure $8 \mathbf{b}, \mathbf{c}$ represent bone graft placement in the right maxillary region. The presence of bone formation can also be seen in the area around the dental implant apex. Several studies have shown satisfactory results in the sinus lifting treatment accompanied by the placement of bone graft material, and this will affect the survival rate of the dental implant [21]. 

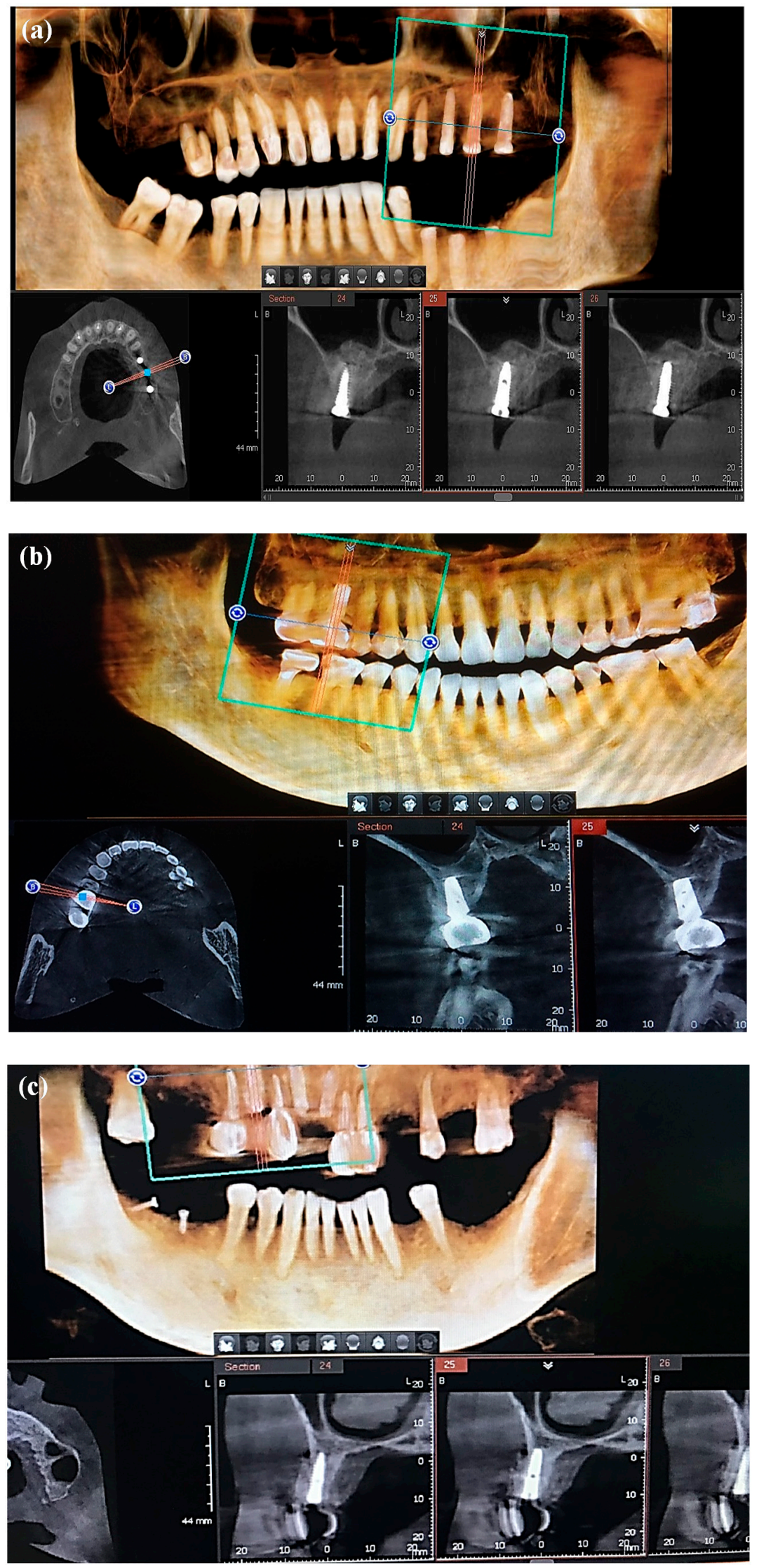

Figure 8. Cone-beam CT images after six months post-treatment in (a) the left maxillary region, (b) right maxillary molar, and (c) right maxillary premolar. 
In the clinical case presented in this study, a CGF membrane was used to cover the $\alpha$-CSH bioceramic bone graft. The use of bone graft following with the CGF membrane on dental implants has been widely reported $[12,48,49]$. The application of the CGF membrane is not only to accelerate bone formation but, also, to aid in soft tissue healing as a consequence of surgical procedures [12,48-51]. The CGF membrane is safe for clinical application due to, during the preparations, it does not require a chemical additive $[12,48,49,51]$.

The use of autologous bone graft and platelet-rich fibrin (PRF) as natural sources has also been reported to be successful in treating bone defects [52,53]. Several harvesting methods such as a traditional (open) method or minimally invasive method can be used to harvest autologous bone grafts, although there have been several controversies in the literature both due to its complications and the need for the bone graft required [54,55]. In general, traditional methods have been used to obtain more bone grafts. However, this method causes more complications than minimally invasive methods. Another study showed both the traditional and minimally invasive method that has no significant difference in morbidity rates [54]. Another issue of using a natural source bone graft is in the use of PRF for the treatment of bone defects. Although the use of PRF alone can be successful in bone formation, its osteogenic ability is still limited compared to using bone graft material due to a lack of rigidity and faster degradation [56]. To solve the issues of using natural sources, in this study, we used $\alpha$-CSH bioceramic as a synthetic bone graft substitute to treat bone defects.

Large bone defects (2-2.5-times larger than the affected bone) would not be ossified naturally $[5,25,57]$. Hence, $\alpha-\mathrm{CSH}$ bioceramic as a substitute bone graft was necessary to treat large bone defects because of its ability to act as a bone formation booster for a short period [18,40,58-60]. The ability of $\alpha$-CSH bioceramic to facilitate new bone formation is related to the absorption of this material in the defect area $[18,23,41,59]$. The absorption time of calcium sulfate varies widely from one-three months after treatment $[23,40,61]$. The rapid absorption of calcium sulfate provides a large supply of calcium ions revealed by a more radiopaque image on the radiograph $[19,41,59]$. In the absorption process, osteoclasts will absorb calcium sulfate as the absorbing bone, preventing osteoclast activity in the bone and promoting osteoblast activity by increasing the concentration of osteoprogenitor cells that play a role in the bone-formation process $[18,19,25,40,41,58,60,62]$. Several studies have also reported the success of using calcium sulfate bone graft in patients with bone infections $[23,58,63]$. Due to the ability of calcium sulphate to create an acid environment that is unfavorable for bacteria, causes this material to be recommended in cases of bone defect treatments as the consequences of osteomyelitis and tumor resection $[23,62,63]$.

Another advantage of using $\alpha$-CSH bioceramic as the bone graft is a micro/nano-sized powder characteristic that easily mixes with various liquids and adapts well to the various shapes of bone defects $[35,61,64]$. Furthermore, the setting time of this material is acceptable for use in a wide range of surgical and clinical applications, which allows the clinician to place it in the defect area before it hardens $[35,65]$.

The analysis results that were found above support the $\alpha$-CSH bioceramic properties for use as a bone graft in the treatment of bone defects. However, further study is needed for clinical studying with a larger sample size to strengthen the evidence of the effectiveness of the $\alpha$-CSH bioceramic as a bone graft substitute in the treatment of bone defects.

\section{Conclusions}

The morphology and composition analysis results indicate that the $\alpha$-CSH bioceramic bone graft is a uniform-shaped short column crystal containing high calcium, which is important for bone demineralization. In the thermal observation, the $\alpha$-CSH bioceramic shows the ideal setting time and low temperature during the setting. Histological findings in an animal study indicated that the $\alpha$-CSH bioceramic is an absorbable material and has a favorable healing process. Moreover, the observation from the clinical application showed the presence of intact bone in the bone defect after being treated 
with an $\alpha$-CSH bioceramic. Therefore, the $\alpha$-CSH bioceramic is useful as a bone graft substitute in bone defect treatments.

Author Contributions: Investigation, S.S.; resources, Y.-C.C. methodology, B.-H.H. and M.-S.H.; data curation, W.-C.L. and C.-H.T.; supervision; C.-M.L. and T.U.; validation, T.S.; writing-original draft, S.S.; and writing-review and editing, M.-S.C. and K.-L.O. All authors have read and agreed to the published version of the manuscript.

Funding: The authors would like to thank the Ministry of Science and Technology, Taiwan for financially supporting this research under contract No. MOST 109-2622-8-039-003-TB1.

Acknowledgments: The authors would like to thank Chi-Yang Lo for his helpful advice and technical support in the clinical trials investigated in this paper.

Conflicts of Interest: The authors declare no conflict of interest.

\section{References}

1. Smrke, D.; Roman, P.; Veselko, M.; Gubi, B. Treatment of bone defects—allogenic platelet gel and autologous bone technique. Regenerat. Med. Tissue Eng. 2013. [CrossRef]

2. Wiese, A.; Pape, H.C. Bone defects caused by high-energy injuries, bone loss, infected nonunions, and nonunions. Orthop. Clin. North Am. 2010, 41, 1-4. [CrossRef] [PubMed]

3. Titsinides, S.; Agrogiannis, G.; Karatzas, T. Bone grafting materials in dentoalveolar reconstruction: A comprehensive review. Jpn. Dent. Sci. Rev. 2019, 55, 26-32. [CrossRef]

4. Fernandez de Grado, G.; Keller, L.; Idoux-Gillet, Y.; Wagner, Q.; Musset, A.-M.; Benkirane-Jessel, N.; Bornert, F.; Offner, D. Bone substitutes: A review of their characteristics, clinical use, and perspectives for large bone defects management. J. Tissue Eng. 2018, 9, 18. [CrossRef] [PubMed]

5. Wu, V.; Helder, M.N.; Bravenboer, N.; Ten Bruggenkate, C.M.; Jin, J.; Klein-Nulend, J.; Schulten, E. Bone tissue regeneration in the oral and maxillofacial region: A review on the application of stem cells and new strategies to improve vascularization. Stem Cells Int. 2019, 2019, 6279721. [CrossRef] [PubMed]

6. Alfotawi, R.; Ayoub, A. reconstruction of maxillofacial bone defects: Contemporary methods and future techniques. Am. J. Adv. Med. Sci. 2014, 2, 10.

7. Gjerde, C.; Mustafa, K.; Hellem, S.; Rojewski, M.; Gjengedal, H.; Yassin, M.A.; Feng, X.; Skaale, S.; Berge, T.; Rosen, A.; et al. Cell therapy induced regeneration of severely atrophied mandibular bone in a clinical trial. Stem Cell Res. Ther. 2018, 9, 213. [CrossRef] [PubMed]

8. Kheirallah, M.; Almeshaly, H. Bone graft substitutes for bone defect regeneration. A collective review. Int. J. Dent. Oral Sci. 2016, 247-255. [CrossRef]

9. Haugen, H.J.; Lyngstadaas, S.P.; Rossi, F.; Perale, G. Bone grafts: Which is the ideal biomaterial? J. Clin. Periodontol. 2019, 46 (Suppl. 21), 92-102. [CrossRef]

10. Khodakaram-Tafti, A.; Mehrabani, D.; Shaterzadeh-Yazdi, H.; Zamiri, B.; Omidi, M. Tissue engineering in maxillary bone defects. World J. Plast. Surg. 2018, 7, 9.

11. Faverani, L.P.; Ramalho-Ferreira, G.; Santos, P.H.; Rocha, E.P.; Garcia Junior, I.R.; Pastori, C.M.; Assuncao, W.G. Surgical techniques for maxillary bone grafting-Literature review. Rev. Col. Bras. Cir. 2014, 41, 7. [CrossRef] [PubMed]

12. Cruz, A.D.; Peixoto, G.A.; Aguiar, M.F.; Camargo, G.; Homs, N. Surgeons' Performance determining the amount of graft material for sinus floor augmentation using tomography. Braz. Dent. J. 2017, 28, 385-390. [CrossRef] [PubMed]

13. Khojasteh, A.; Esmaeelinejad, M.; Aghdashi, F. Regenerative techniques in oral and maxillofacial bone grafting. In A Textbook of Advanced Oral and Maxillofacial Surgery; IntechOpen: London, UK, 2015; Volume 2. [CrossRef]

14. Vieira, J.S.; Brandao-Filho, E.M.; Deliberador, F.R.; Zielak, J.C.; Giovanini, A.F.; Deliberador, T.M. Dental implant placement with simultaneous anterior maxillary reconstruction with block and particulate fresh frozen allograft bone: A case report with 24-month follow-up data. Case Rep. Surg. 2017, 2017, 1565973. [CrossRef] [PubMed]

15. Rivara, F.; Negri, M.; Lumetti, S.; Parisi, L.; Toffoli, A.; Calciolari, E.; Manfredi, E.; Macaluso, G.M. Maxillary sinus floor augmentation using an equine-derived graft material: Preliminary results in 17 patients. Biomed. Res. Int. 2017, 2017, 9164156. [CrossRef] 
16. Turri, A.; Dahlin, C. Comparative maxillary bone-defect healing by calcium-sulphate or deproteinized bovine bone particles and extra cellular matrix membranes in a guided bone regeneration setting: An experimental study in rabbits. Clin. Oral Implants Res. 2015, 26, 501-506. [CrossRef]

17. Monje, A.; Urban, I.A.; Miron, R.J.; Caballe-Serrano, J.; Buser, D.; Wang, H.L. Morphologic patterns of the atrophic posterior maxilla and clinical implications for bone regenerative therapy. Int J. Periodont. Restorat. Dent. 2017, 37, e279-e289. [CrossRef]

18. Kashani, H.; Dasmah, A.; Mokhtari, R.; Dahlin, C. Sinus-lift by use of hemihydrate-calcium sulphate: A prospective clinical, radiographical, histological study of implant integration in the posterior maxilla. EC Dent. Sci. 2017, 15, 10.

19. Suleiman, M.S.; Hasouni, M.K. Effect of $\beta$-calcium sulphate hemihydrate on mandible healing in dog (radiographical assessment using Image-J Program). Iraqi J. Vet. Sci. 2014, 28, 10. [CrossRef]

20. Pillai, S.; Ganapathy, D. Bone substitutes for sinus lift. J. Pharm. Sci. Res. 2016, 8, 6.

21. Silva, L.D.; de Lima, V.N.; Faverani, L.P.; de Mendonca, M.R.; Okamoto, R.; Pellizzer, E.P. Maxillary sinus lift surgery-with or without graft material? A systematic review. Int. J. Oral Maxillofac. Surg. 2016, 45, 1570-1576. [CrossRef]

22. Yousefi, A.M. A review of calcium phosphate cements and acrylic bone cements as injectable materials for bone repair and implant fixation. J. Appl. Biomater. Funct. Mater. 2019, 17, 2280800019872594. [CrossRef]

23. Yashavantha, K.C.; Nalini, K.B.; Jagdish Menon, D.K.P.; Banerji, B.H. Calcium sulfate as bone graft substitute in the treatment of osseous bone defects, a prospective study. J. Clin. Diagn. Res. 2013, 7, 2926-2928. [CrossRef]

24. McCall, T.A.; Brokaw, D.S.; Jelen, B.A.; Scheid, D.K.; Scharfenberger, A.V.; Maar, D.C.; Green, J.M.; Shipps, M.R.; Stone, M.B.; Musapatika, D.; et al. Treatment of large segmental bone defects with reamer-irrigator-aspirator bone graft: Technique and case series. Orthop. Clin. North. Am. 2010, 41, 63-73. [CrossRef] [PubMed]

25. Meng, Z.L.; Wu, Z.Q.; Shen, B.X.; Li, H.B.; Bian, Y.Y.; Zeng, L.; Fu, J.; Peng, L. Reconstruction of large segmental bone defects in rabbit using the Masquelet technique with alpha-calcium sulfate hemihydrate. J. Orthop. Surg. Res. 2019, 14, 192. [CrossRef] [PubMed]

26. Jiang, N.; Qin, C.H.; Ma, Y.F.; Wang, L.; Yu, B. Possibility of one-stage surgery to reconstruct bone defects using the modified Masquelet technique with degradable calcium sulfate as a cement spacer: A case report and hypothesis. Biomed. Rep. 2016, 4, 374-378. [CrossRef]

27. Sakkas, A.; Wilde, F.; Heufelder, M.; Winter, K.; Schramm, A. Autogenous bone grafts in oral implantology-is it still a "gold standard"? A consecutive review of 279 patients with 456 clinical procedures. Int. J. Implant. Dent. 2017, 3, 23. [CrossRef]

28. Salamanca, E.; Hsu, C.C.; Huang, H.M.; Teng, N.C.; Lin, C.T.; Pan, Y.H.; Chang, W.J. Bone regeneration using a porcine bone substitute collagen composite in vitro and in vivo. Sci. Rep. 2018, 8, 984. [CrossRef]

29. Maghaireh, H.; Hussain, I. Localized maxillary ridge augmentation using onlay technique with a xenograft block for dental implant placement: A case series. Smile Dent. J. 2012, 7, 6.

30. Ortiz-Vigon, A.; Suarez, I.; Martinez-Villa, S.; Sanz-Martin, I.; Bollain, J.; Sanz, M. Safety and performance of a novel collagenated xenogeneic bone block for lateral alveolar crest augmentation for staged implant placement. Clin. Oral Implants Res. 2018, 29, 36-45. [CrossRef]

31. Scarano, A.; Carinci, F.; Assenza, B.; Piattelli, M.; Murmura, G.; Piattelli, A. Vertical ridge augmentation of atrophic posterior mandible using an inlay technique with a xenograft without miniscrews and miniplates: Case series. Clin. Oral Implants Res. 2011, 22, 1125-1130. [CrossRef]

32. Zafar, M.J.; Zhu, D.; Zhang, Z. 3D Printing of bioceramics for bone tissue engineering. Materials 2019, $12,3361$. [CrossRef] [PubMed]

33. Favvas, E.P.; Stefanopoulos, K.L.; Vordos, N.C.; Drosos, G.I.; Mitropoulos, A.C. Structural characterization of calcium sulfate bone graft substitute cements. Mater. Res. 2016, 19, 1108-1113. [CrossRef]

34. Thomas, M.V.; Puleo, D.A. Calcium sulfate: Properties and clinical applications. J. Biomed. Mater. Res. B Appl. Biomater. 2009, 88, 597-610. [CrossRef] [PubMed]

35. Al-Haddad, A.; Che Ab Aziz, Z.A. Bioceramic-based root canal sealers: A review. Int. J. Biomater. 2016, 2016, 9753210. [CrossRef] [PubMed]

36. Scarano, A.; Quaranta, A.; Feregalli, B.; Di Cristinzi, A.; Carinci, F.; Lauritano, D. Haemostasis control in dental extraction with calcium sulphate: A case series. Eur. J. Inflamm. 2012, 10, 5. 
37. Scarano, A.; Sinjari, B.; Murmura, G.; Mijiritsky, E.; Iaculli, F.; Mortellaro, C.; Tete, S. Hemostasis control in dental extractions in patients receiving oral anticoagulant therapy: An approach with calcium sulfate. J. Craniofac. Surg. 2014, 25, 843-846. [CrossRef]

38. Jang, Y.; Kim, H.; Roh, B.D.; Kim, E. Biologic response of local hemostatic agents used in endodontic microsurgery. Restorat. Dent. Endodont. 2014, 39, 79-88. [CrossRef]

39. Menendez Nieto, I.; Cervera Ballester, J.; Penarrocha Diago, M.; Penarrocha Oltra, D. New perspectives in periapical surgery: Hemostasis. J. Oral Sci. Rehabilit. 2018, 4, 4.

40. Ou, K.-L.; Hou, P.-J.; Huang, B.-H.; Chou, H.-H.; Yang, T.-S.; Huang, C.-F.; Ueno, T. Bone healing and regeneration potential in rabbit cortical defects using an innovative bioceramic bone graft substitute. Appl. Sci. 2020, 10, 6239. [CrossRef]

41. Hsu, H.-J.; Waris, R.A.; Ruslin, M.; Lin, Y.-H.; Chen, C.-S.; Ou, K.-L. An innovative $\alpha$-calcium sulfate hemihydrate bioceramic as a potential bone graft substitute. J. Am. Ceram. Soc. 2017, 101, 419-427. [CrossRef]

42. Dunne, N.; Ormsby, R.W. MWCNT Used in Orthopaedic Bone Cements; IntechOpen: London, UK, 2011.

43. Liptakova, T.; Lelovics, H.; Necas, L. Variations of temperature of acrylic bone cements prepared by hand and vacuum mixing during their polymerization. Acta Bioeng. Biomech. 2009, 11, 5.

44. Abu Zeid, S.T.; Mokeem Saleh, A.A.; Khafagi, M.G.E.-D.; Abou Neel, E.A. Setting reaction of new bioceramic root canal sealers. Spectrosc. Lett. 2018, 51, 426-430. [CrossRef]

45. Gupta, A.; Kumar, P. Assessment of the histological state of the healing wound. Plast. Aesthet. Res. 2015, 2, 239-242. [CrossRef]

46. Sculean, A.; Stavropoulos, A.; Bosshardt, D.D. Self-regenerative capacity of intra-oral bone defects. J. Clin. Periodontol. 2019, 46 (Suppl. 21), 70-81. [CrossRef]

47. Hori, M.; Kaneko, K.; Harada, D.; Nakanishi, K.; Tanaka, T.; Ishii, T.; Tanaka, H. Treatment planning in a case of restoration of the maxilla and mandible using osseointegrated with four types of bone graft. J. Oral Sci. 2003, 45, 6. [CrossRef]

48. Pirpir, C.; Yilmaz, O.; Candirli, C.; Balaban, E. Evaluation of effectiveness of concentrated growth factor on osseointegration. Int. J. Implant. Dent. 2017, 3, 7. [CrossRef]

49. Tabatabaei, F.; Aghamohammadi, Z.; Tayebi, L. In vitro and in vivo effects of concentrated growth factor on cells and tissues. J. Biomed. Mater. Res. A 2020, 108, 1338-1350. [CrossRef]

50. Begum, M.; Reddy, J.T.; Kumar, K.V.S.; Naik, P.M. Concentrated growth factor (CGF) in alveolar bone grafting procedures: Dilemma or a reality? A detailed review. Glob. J. Med. Res. 2019, 19, 6.

51. Kumar, Y.P. Role of CGF (Concentrated Growth Factor) in periodontal regeneration. J. Dent. Health Oral Dis. Ther. 2018, 9, 350-352. [CrossRef]

52. Crespi, R.; Vinci, R.; Cappare, P.; Gherlone, E.; Romanos, G.E. Calvarial versus iliac crest for autologous bone graft material for a sinus lift procedure: A histomorphometric study. Int. J. Oral Maxillofac. Implants 2007, 22,6 .

53. Moraschini, V.; Mourão, C.F.d.A.B.; Machado, R.C.d.M.; Nascimento, J.R.B.; Javid, K.; Calasans-Maia, M.D.; Cardarelli, A.; Montemezzi, P.; Calasans-Maia, J.d.A. Does platelet-rich fibrin decrease dimensional changes and improve postoperative comfort in post-extraction sockets? An overview of systematic reviews. Appl. Sci. 2020, 10. [CrossRef]

54. Dimitriou, R.; Mataliotakis, G.I.; Angoules, A.G.; Kanakaris, N.K.; Giannoudis, P.V. Complications following autologous bone graft harvesting from the iliac crest and using the RIA: A systematic review. Injury 2011, 42 (Suppl. 2), S3-S15. [CrossRef] [PubMed]

55. Saha, A.; Shah, S.; Waknis, P.; Bhujbal, P.; Aher, S.; Vaswani, V. Comparison of minimally invasive versus conventional open harvesting technique for iliac bone graft in secondary alveolar bone grafting in cleft palate patients: A systematic review. J. Korean Assoc. Oral Maxillofac. Surg. 2019, 45, 241-253. [CrossRef] [PubMed]

56. Liu, Y.; Sun, X.; Yu, J.; Wang, J.; Zhai, P.; Chen, S.; Liu, M.; Zhou, Y. Platelet-rich fibrin as a bone graft material in oral and maxillofacial bone regeneration: Classification and summary for better application. Biomed. Res. Int. 2019, 2019, 3295756. [CrossRef]

57. Wang, W.; Yeung, K.W.K. Bone grafts and biomaterials substitutes for bone defect repair: A review. Bioact. Mater. 2017, 2, 224-247. [CrossRef]

58. Borrelli, J., Jr.; Prickett, W.D.; Ricci, W.M. Treatment of nonunions and osseous defects with bone graft and calcium sulfate. Clin. Orthop. Relat. Res. 2003, 411, 245-254. [CrossRef] [PubMed] 
59. Szponder, T.; Mytnik, E.; Jaegermann, Z. Use of calcium sulfate as a biomaterial in the treatment of bone fractures in rabbits-preliminary studies. Bull. Vet. Inst. Pulawy 2013, 57, 119-122. [CrossRef]

60. Yang, B.C.; Lee, J.W.; Ju, C.P.; Chern Lin, J.H. Physical/chemical properties and resorption behavior of a newly developed $\mathrm{Ca} / \mathrm{P} / \mathrm{S}$-based bone substitute material. Materials 2020, 13, 3458. [CrossRef]

61. Lei, D.; Zhanzhong, M.; Huaikuo, Y.; Lei, X.; Gongbo, Y. Treatment of Distal Radius Bone Defects with Injectable Calcium Sulphate Cement, Bone Grafting; IntechOpen: London, UK, 2012.

62. Mukherji, A.; Rath, S. Calcium sulfate in periodontics: A time tested versatile alloplast. J. Sci. Soc. 2016, 43, 18. [CrossRef]

63. Menendez, L.R.; Mirzayan, R.; Samimi, B.; Lindberg, A.W.; Allison, D.C. A comparison of mineral bone graft substitutes for bone defects. Oncol. Hematol. Rev. 2011, 7, 38-49. [CrossRef]

64. Wang, P.; Pi, B.; Wang, J.-N.; Zhu, X.-S.; Yang, H.-L. Preparation and properties of calcium sulfate bone cement incorporated with silk fibroin and Sema3A-loaded chitosan microspheres. Front. Mater. Sci. 2015, 9, 51-65. [CrossRef]

65. Hesaraki, S.; Moztarzadeh, F.; Nemati, R.; Nezafati, N. Preparation and characterization of calcium sulfate-biomimetic apatite nanocomposites for controlled release of antibiotics. J. Biomed. Mater. Res. B Appl. Biomater. 2009, 91, 651-661. [CrossRef] [PubMed]

Publisher's Note: MDPI stays neutral with regard to jurisdictional claims in published maps and institutional affiliations.

(C) 2020 by the authors. Licensee MDPI, Basel, Switzerland. This article is an open access article distributed under the terms and conditions of the Creative Commons Attribution (CC BY) license (http://creativecommons.org/licenses/by/4.0/). 